\title{
APPROXIMATING THE ADDED RESISTANCE COEFFICIENT FOR A BULK CARRIER SAILING IN HEAD SEA CONDITIONS BASED ON ITS GEOMETRICAL PARAMETERS AND SPEED
}

\author{
Tomasz Cepowski, Prof. \\ Maritime University of Szczecin, Poland
}

\begin{abstract}
The article presents the mathematical function to calculate the added wave resistance transfer function for bulk carriers. Based on this function, the statistical mean added wave resistance generated by an irregular head wave with arbitrary statistical parameters can be forecasted. The input parameters are: waterplane area, waterplane coefficient, ship speed, and frequency of the regular wave. The model has been developed based on the theory of artificial neural networks. The presented function can be used in design analyses, and for planning shipping routes in situations when basic geometrical parameters of the hull are only available and not the full technical documentation. The article presents sample cases of use of this function to calculate the added wave resistance transfer function and the statistical mean added wave resistance. Another presented application refers to waterplane coefficient optimisation taking into account the added wave resistance at the stage of preliminary bulk carrier design.
\end{abstract}

Keywords: bulk carrier; resistance; added wave resistance; added resistance coefficient; regular wave; irregular wave; ship designing; preliminary design stage; artificial neural networks; approximation; forecasting; speed; waterplane area; waterplane coefficient, sample case, task, designing

\section{INTRODUCTION}

Assumptions concerning the design of a floating object designed for arbitrary purposes usually include two basic groups of requirements, which are [9]:

- economic requirements,

- technical requirements.

Meeting the first group of requirements usually means realisation of ship function at minimal financial costs of building and maintenance of the object, while meeting the other group is equivalent to object's ability to keep afloat and possess other technical features which will secure safety of the performed operations. To meet the above requirements, a so-called design goal and design constraints are formulated.

For bulk carriers, the design goals are mainly the result of the transport study. According to [17], basic design goals for the bulk carrier refer to:

1. mass of the cargo to be transported,
2. operating speed of the ship, shipping route, and the distance between transhipment ports.

Reaching the assumed operating speed by the bulk carrier depends, among other factors, on operating parameters and conditions of the propulsion system, the efficiency of the propulsion system and hull, and the total hull resistance.

Among other components, the total hull resistance includes the added wave resistance, which $[3,10]$ :

- is connected with ship navigation in storm waves,

- can contribute to about 30-50\% of total ship resistance,

- leads to remarkable drop of operating speed,

- depends on, among other factors, hull dimensions and shape.

That is why forecasting the added wave resistance of the ship is a considerable challenge for ship designers, due to economic aspects of selection of ship propulsion parameters and assessment of fuel consumption and time of voyage, as 
well because of the need to improve energy efficiency of ship operation.

Forecasting the added wave resistance is also an important element of various shipping route planning systems. When the detailed data on ship resistance-propulsion characteristics taking into account the added wave resistance and hull geometry are missing, these characteristics are to be forecasted using simplified methods.

\section{THE ADDED WAVE RESISTANCE}

Accounting methods used to assess the added wave resistance are limited to resistance calculations for the head wave. These methods base on the assumption that the added resistance has the nature of wave resistance and does not depend on the calm water resistance [10]. The mean added wave resistance is calculated using the function which initially describes the resistance contribution from a regular (sine) wave, $R_{A W}\left(\omega_{E}\right)$. Then, applying the superposition principle to the spectral distribution of the irregular wave (given by function $S_{\zeta \zeta}\left(\omega_{E}\right)$ ), the increase of the statistical mean resistance $R_{w}$ in irregular (statistical) wave is calculated as [10]:

$$
R_{w}=\int_{0}^{\infty} \frac{R_{A W}\left(\omega_{E}\right)}{\zeta_{a}^{2}} S_{\zeta \zeta}(\omega
$$

where:

$R_{w}$ - statistical mean wave resistance increase,

$R_{A W}$ - added resistance from the regular wave,

$\omega_{E}$ - encounter frequency of the harmonic wave,

$\zeta_{a}$ - amplitude of the regular wave,

$S_{\zeta \zeta}$ - wave energy spectrum density function.

The proportionality of the added resistance $R_{A W}$ to the square of the regular wave amplitude $\zeta_{a}$ makes it possible to calculate the dimensionless added wave resistance coefficient $\rho_{A W}[10]:$

where:

$$
\rho_{A W}=\frac{R_{A W}}{\zeta_{a}^{2} \rho g \frac{B^{2}}{L}}
$$

$\rho A W$ - dimensionless added wave resistance coefficient,

$B$ - ship breadth,

$L$ - ship length,

$\rho$ - seawater density,

$g$ - acceleration due to gravity.

The added resistance from regular wave is calculated using various methods, most frequently the Gerritsma-Beukelman method [12] or the Boese method [10].The former method is simpler and provides results which are relatively well in line with the experiment [10]. However, calculating the dimensionless added wave resistance coefficient with the aid of this method requires the use of numerical calculations and the knowledge of the geometrical shape of the hull.

Simplified methods to calculate the added wave resistance which are presented in $[3,4,15]$ can only be applied to a given hull. They enable to calculate the added resistance from an irregular wave. In turn, the methods presented in $[5,6,8]$ omit the effect of ship speed on the wave resistance and enable to calculate the resistance contribution only from a so-called statistical wave.

In [7], in turn, a simplified method is presented which enables to calculate the added wave resistance coefficient as a function of design parameters of the ship. In this method, the added resistance coefficient is initially parameterised based on the simplified model [7]:

where:

$$
\rho_{A W}=\frac{a \cdot \omega}{\sqrt{\left(1-\frac{\omega^{2}}{\omega_{0}^{2}}\right)^{2}+\left(b \cdot \frac{\omega}{\omega_{0}}\right)^{2}}}
$$

$\rho_{A W}$ - approximated dimensionless added wave resistance coefficient,

$\omega$ - wave frequency,

$a, b, \omega_{0}$ - parameters depending on geometrical parameters of the ship hull.

The results obtained using this method allow to assess, within the linear theory of rolling, statistical values of the added resistance from an arbitrary irregular wave described by the wave energy spectrum density function.

The dimensionless resistance coefficient is calculated using the method [7] in two stages:

1. calculating the values of the coefficients $a, b, \omega_{0}$ in model

(3) in such a way that the function (3) best fits the reference data,

2. calculating the functions which approximate the parameters $a, b, \omega_{0}$ based on the design parameters of the ship.

Since the approximation is done in two stages, its accuracy is relatively low while the calculation model is complicated. Moreover, the method does not take into account the effect of speed change on this coefficient and only refers to container ships within a narrow range of dimensions.

\section{APPROXIMATING THE ADDED WAVE RESISTANCE COEFFICIENT}

Taking into account the above discussed aspects, the goal of the research reported in the article was to develop an approximating function for the added wave resistance which will depend on:

- encounter frequency of the regular wave,

- ship speed,

- basic design parameters of the hull.

As the first step, making use of the method [12], the reference values of the added resistance coefficient were calculated for the group of hulls of bulk carriers collated in Table 1. The calculations were performed using the code SEAWAY which, based on the theory of 2D flow, calculates the ship motion in regular an irregular wave. The results presented in [13] testify to high accuracy of this code and compliance with the results of measurements recorded in the model basin.

The calculations were performed under the following assumptions: 
- geometrical shape of each bulk carrier is given by theoretical lines,

- ship speed range is within: $\mathrm{v}=0-8 \mathrm{~m} / \mathrm{s}$,

- wave frequency is: $\mathrm{w}=0,25-0,95 \mathrm{~s}^{-1}$.

Table 1. Parameters describing hulls of bulk carriers for which the reference values of the dimensionless resistance coefficient were calculated: $L_{p p}$ - length between perpendiculars, $B$ - breadth

$T$-draught, $F_{w}$ - waterplane area, $C W L$ - waterplane coefficient, $D$ - mass displacement.

\begin{tabular}{|c|c|c|c|c|c|c|}
\hline $\mathrm{Lp}$ & $\mathrm{L}_{\mathrm{pp}}[\mathrm{m}]$ & $\mathrm{B}[\mathrm{m}]$ & $\mathrm{T}[\mathrm{m}]$ & $\mathrm{Fw}\left[\mathrm{m}^{2}\right]$ & $\mathrm{CWL}[-]$ & $\mathrm{D}[\mathrm{t}]$ \\
\hline 1 & 185 & 24,4 & 11,01 & 3938 & 0,8725 & 41849 \\
\hline 2 & 140,1 & 22,3 & 10,95 & 2921 & 0,9348 & 25379 \\
\hline 3 & 185 & 25,3 & 10,65 & 3987 & 0,8518 & 40837 \\
\hline 4 & 187 & 29 & 10,95 & 4693 & 0,8653 & 48395 \\
\hline 5 & 167 & 22,86 & 10,87 & 3381 & 0,8856 & 34334 \\
\hline 6 & 172 & 23,1 & 7,86 & 3398 & 0,8553 & 26109 \\
\hline 7 & 132 & 21 & 8,53 & 2309 & 0,833 & 18446 \\
\hline 8 & 173 & 25,3 & 10 & 3526 & 0,8056 & 30385 \\
\hline 9 & 210 & 32,26 & 10,5 & 5622 & 0,8299 & 46818 \\
\hline 10 & 175,4 & 32,2 & 12 & 5067 & 0,8971 & 56232 \\
\hline 11 & 160 & 25,3 & 10 & 3298 & 0,8148 & 27935 \\
\hline
\end{tabular}

The reference data set created in the above way was used, along with various approximation methods, to develop the function approximating the added wave resistance coefficient. The above function depends on:

- waterplane area and waterplane coefficient,

- ship speed,

- regular wave frequency.

The approximation was done using the following methods: linear regression,

nonlinear regression,

artificial neural networks.

The approximations making use of linear and nonlinear regression turned out too inaccurate.

More accurate results were obtained using the method based on the theory of artificial neural networks. In many research activities in the fields of hydromechanics and ship designing $[1,2]$ for instance, this method brought very good solutions.

The tested neural network types included:

- multilayer perceptron MLP,

- generalized regression neural network GRNN,

- radial basis function network RBF,

- linear networks.

From among all those network types, the best solution was obtained using the neural network MLP having the following structure: 4 neurons in the input layer, 9 neurons in the hidden layer, and 1 neuron in the output layer. The structure of this network is graphically shown in Fig. 1, while its mathematical form is given by the following relations:

$$
\rho_{\mathrm{AW}}=\frac{c}{0,093}
$$

where:

$\rho_{A W}$ - the approximated dimensionless added wave resistance coefficient [-], $c$ - the variable calculated from the relation:

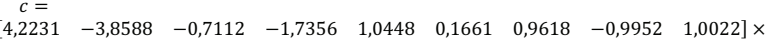

where:

A - column matrix:

$$
A=\left[\begin{array}{l}
\frac{1}{1+e^{-a_{1}}} \\
\frac{1}{1+e^{-a_{2}}} \\
\frac{1}{1+e^{-a_{3}}} \\
\frac{1}{1+e^{-a_{4}}} \\
\frac{1}{1+e^{-a_{5}}} \\
\frac{1}{1+e^{-a_{6}}} \\
\frac{1}{1+e^{-a_{7}}} \\
\frac{1}{1+e^{-a_{8}}} \\
\frac{1}{1+e^{-a_{9}}}
\end{array}\right]
$$

where:

$\left[\begin{array}{l}a_{1} \\ a_{2} \\ a_{3} \\ a_{4} \\ a_{5} \\ a_{6} \\ a_{7} \\ a_{8} \\ a_{9}\end{array}\right]=\left[\begin{array}{cccc}0,0486 & 0,1848 & 3,024 & 17,7772 \\ 0,5403 & 0,2205 & 2,6284 & 18,8042 \\ 1,3183 & -2,1168 & 1,100 & 3,0319 \\ -1,431 & 1,7161 & 0,636 & -0,3537 \\ -1,0826 & 1,4126 & 1,4063 & 2,968 \\ -0,3303 & -0,3019 & 2,075 & 0,2037 \\ -1,8584 & 0,375 & 1,5476 & 0,5624 \\ -1,8994 & 0,3979 & 0,7193 & 2,5233 \\ 0,2652 & -0,6208 & -0,828 & 1,4015\end{array}\right] \times\left[\begin{array}{c}b_{1} \\ b_{2} \\ b_{3} \\ b_{4}\end{array}\right]-\left[\begin{array}{c}10,2767 \\ 11,284 \\ 2,102 \\ -2,1791 \\ -0,7662 \\ -1,8044 \\ 0,0735 \\ -0,0256 \\ -0,626\end{array}\right]$

where:

$$
\begin{gathered}
b_{1}=F_{w} \cdot 0,0003-0,697 \\
b_{2}=C W L \cdot 7,7399-6,2353 \\
b_{3}=V \cdot 0,0667
\end{gathered}
$$

$$
b_{4}=\omega_{E} \cdot 1,4229-0,3486
$$

where:

$\mathrm{F}_{\mathrm{w}}$ - waterplane area $\left[\mathrm{m}^{2}\right]$,

CWL - waterplane coefficient [-],

$\mathrm{V}$ - ship speed $[\mathrm{w}]$,

$\omega_{\mathrm{E}}-$ wave encounter frequency $[1 / \mathrm{s}]$,

Table 2 presents statistical parameters of the developed approximation with respect to the reference data, broken down by:

- data used for network teaching - teaching set,

- data used for network validation during its teaching validation set,

- data used only for network testing - test set. 
Of particular significance here are the statistics for the test values. The statistic values shown in Table 2 testify to high anticipatory ability of this network, even for test data which were not used for network development.

Table 2 Statistical parameters of artificial neural network described by Equation (4)

\begin{tabular}{|c|c|c|c|}
\hline & $\begin{array}{c}\text { Teaching } \\
\text { set }\end{array}$ & $\begin{array}{c}\text { Validation } \\
\text { set }\end{array}$ & Test set \\
\hline Mean absolute error [-] & 0,39 & 0,46 & 0,39 \\
Correlation coefficient [-] & 0,96 & 0,95 & 0,96 \\
\hline
\end{tabular}

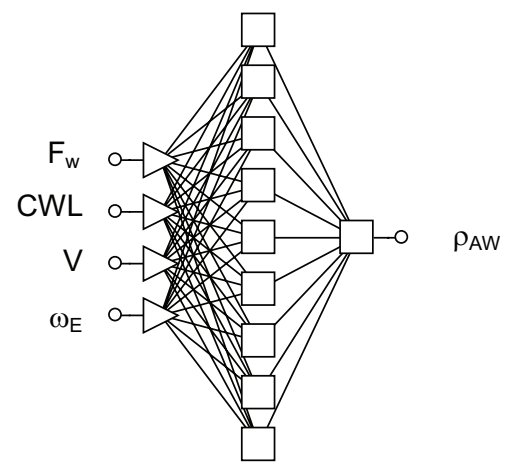

Fig. 1 Structure of the artificial neural network described by Equation (4): Fw - waterplane area, CWL - waterplane coefficient, $V$ - ship speed, $\omega_{E}$ encounter frequency, $\rho_{A W}$ - added resistance coefficient.

Figure 2 compares the reference data with the values calculated using formula (4), while Fig. 3 presents the reference values of the added resistance coefficient, calculated for the bulk carrier No. 4 from Table 1 and the values calculated using formula (4) within a wide ship speed range. Figure 4, in turn, compares the reference values of the added resistance coefficient obtained from formula (4) and using the methods $[11,16]$ presented in the publication [14] for the bulk carrier "Stara Platina" having parameters: $\mathrm{F}_{\mathrm{w}}=4779 \mathrm{~m}^{2}, \mathrm{CWL}=$ 0,9 and the Froude number $\mathrm{Fr}=0.2$. It results from these diagrams that the approximation (4) reveals relatively high accuracy as compared to other methods, in particular to the method [16].

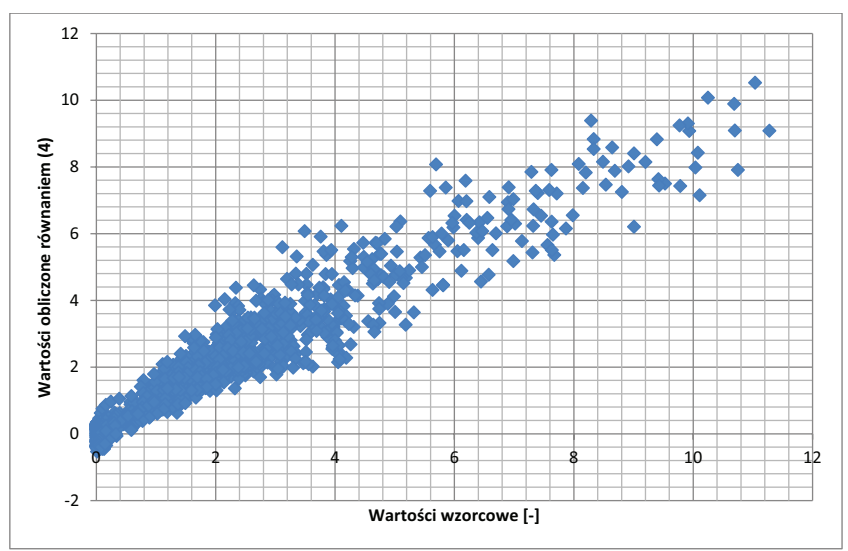

Fig. 2. Reference values of the added wave resistance coefficient vs. results obtained from Equation (4).

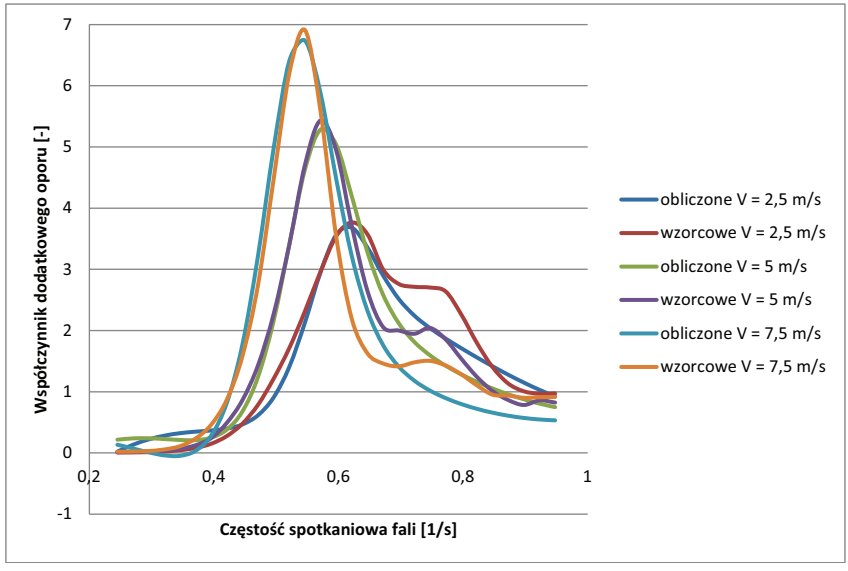

Fig. 3. Reference values of the added wave resistance coefficient vs. results obtained from Equation (4) for the bulk carrier having the parameters: $F_{w}=$ $4693 \mathrm{~m}^{2}, \mathrm{CWL}=0,8653$

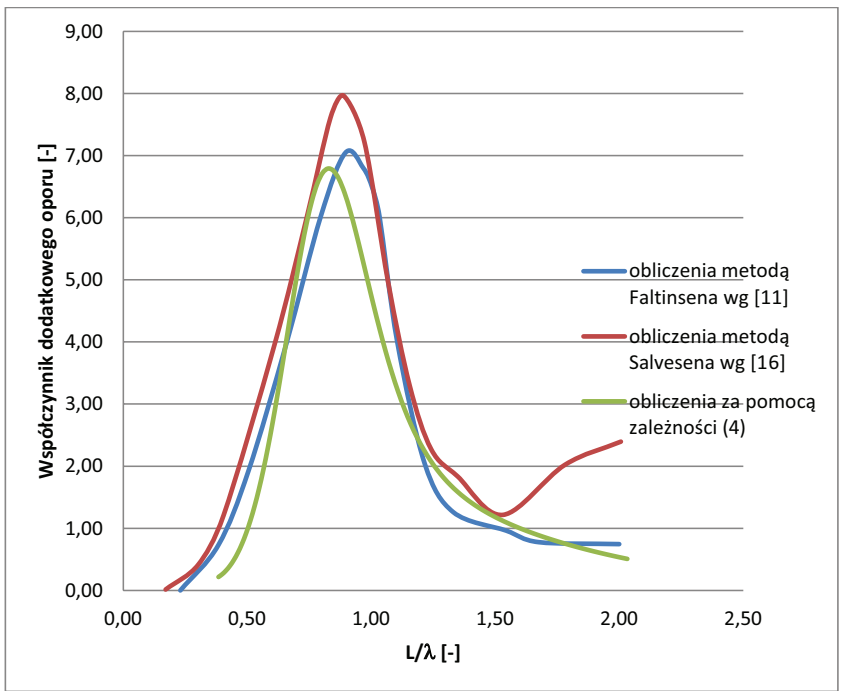

Fig. 4. Comparing the added wave resistance coefficient values obtained from Equation (4) and using methods [11,16] presented in publication [14] for the bulk carrier "Stara Platina" having the parameters: $F w=4779 \mathrm{~m} 2, \mathrm{CWL}=$ 0,9 , Froude number $\mathrm{Fr}=0.2$

The further part of the article presents examples of practical use of the developed formula (4) for:

- calculating the added wave resistance coefficient $\rho A W$ for constant encounter frequency $\omega \mathrm{E}=0,5 \mathrm{~s}^{-1}$ - case 1 ,

- calculating the statistical mean wave resistance increase - case 2.

The calculations were performed under the following assumptions:

- the ship length between perpendiculars $\mathrm{L}_{\mathrm{pp}}=187 \mathrm{~m}$,

- ship breadth $B=29 \mathrm{~m}$,

- waterplane coefficient CWL $=0,85$

- ship speed V = $15 \mathrm{w}$. 
Case 1. Calculating the added wave resistance coefficient $\rho_{\text {AW for }}$ constant encounter frequency $\omega_{\mathrm{E}}=0,5 \mathrm{~s}^{-1}$

In the first stage, using formulas (8) - (11) the values of coefficients $b_{1}, \ldots, b_{4}$ were calculated as:

$b_{1}=F_{w} \cdot 0,0003-0,697=L_{p p} \cdot B \cdot C W L \cdot 0,0003-0,697=187 \cdot 29 \cdot 0,85 \cdot 0,0003-$
$0,697=0,6859$

$b_{2}=C W L \cdot 7,7399-6,2353=0,85 \cdot 7,7399-6,2353=0,3436$

$$
b_{3}=V \cdot 0,0667=15 \cdot 0,0667=1,0005
$$

$b_{4}=\omega_{E} \cdot 1,4229-0,3486=0,5 \cdot 1,4229-0,3486=0,3629$

Then, using formula (7), the values of coefficients $a_{1}, \ldots$, $a_{9}$ were calculated as:

$\left[\begin{array}{l}a_{1} \\ a_{2} \\ a_{3} \\ a_{4} \\ a_{5} \\ a_{6} \\ a_{7} \\ a_{8} \\ a_{9}\end{array}\right]=\left[\begin{array}{cccc}0,0486 & 0,1848 & 3,024 & 17,7772 \\ 0,5403 & 0,2205 & 2,6284 & 18,8042 \\ 1,3183 & -2,1168 & 1,100 & 3,0319 \\ -1,431 & 1,7161 & 0,636 & -0,3537 \\ -1,0826 & 1,4126 & 1,4063 & 2,968 \\ -0,3303 & -0,3019 & 2,075 & 0,2037 \\ -1,8584 & 0,375 & 1,5476 & 0,5624 \\ -1,8994 & 0,3979 & 0,7193 & 2,5233 \\ 0,2652 & -0,6208 & -0,828 & 1,4015\end{array}\right] \times\left[\begin{array}{c}0,6859 \\ 0,3436 \\ 1,0005 \\ 0,3629\end{array}\right]-\left[\begin{array}{c}10,2767 \\ 11,284 \\ 2,102 \\ -2,1791 \\ -0,7662 \\ -1,8044 \\ 0,0735 \\ -0,0256 \\ -0,626\end{array}\right]=\left[\begin{array}{c}-0,7031 \\ -1,3839 \\ 0,2758 \\ 2,2952 \\ 2,9931 \\ 3,624 \\ 0,5332 \\ 0,4949 \\ 0,2748\end{array}\right]$

Placing the values of coefficients $a_{1}, \ldots, a_{9}$ calculated using formula (16) to formula (6), we got the single column matrix A in the form:

$$
A=\left[\begin{array}{l}
\frac{1}{1+e^{-(-0,7031)}} \\
\frac{1}{1+e^{-(-1,3839)}} \\
\frac{1}{1+e^{-0,2758}} \\
\frac{1}{1+e^{-2,2952}} \\
\frac{1}{1+e^{-2,9931}} \\
\frac{1}{1+e^{-3,624}} \\
\frac{1}{1+e^{-0,5332}} \\
\frac{1}{1+e^{-0,4949}} \\
\frac{1}{1+e^{-0,2748}}
\end{array}\right]=\left[\begin{array}{c}
0,3311 \\
0,2004 \\
0,5685 \\
0,9085 \\
0,9523 \\
0,974 \\
0,6302 \\
0,6213 \\
0,5683
\end{array}\right]
$$

Then, making use of Equation (5) we got the value of coefficient $c$ :

$\begin{array}{lllllllll}c= & & & & & \\ {[4,2231} & -3,8588 & -0,7112 & -1,7356 & 1,0448 & 0,1661 & 0,9618 & -0,9952 & 1,0022] \times\end{array}$

and making use of formula (4) we finally got:

$$
\left[\begin{array}{c}
0,3311 \\
0,2004 \\
0,5685 \\
0,9085 \\
0,9523 \\
0,974 \\
0,6302 \\
0,6213 \\
0,5683
\end{array}\right]+0,1322=0,4903
$$

The formula (17) represents the value of the added wave resistance coefficient for the assumed encounter frequency equal to $\omega_{\mathrm{E}}=0,5 \mathrm{~s}^{-1}$.
Case 2. Calculating the statistical mean wave resistance increase

Making use of the superposition principle applied to spectral representation of the irregular wave and transforming formulas (1) and (2) we can calculate the increase of the statistical mean wave resistance $\mathrm{R}_{\mathrm{w}}$ coming from an irregular wave. For this purpose, we use the following formula:

$$
R_{w}=\rho \cdot g \cdot \frac{B^{2}}{L} \int_{0}^{\infty} \rho_{A W}\left(\omega_{E}\right) \cdot S_{\zeta \zeta}\left(\omega_{E}\right) d \omega_{E}
$$

where:

$R_{w}$ - statistical mean wave resistance increase,

$\omega_{E}$ - encounter frequency of the harmonic wave,

$S_{\zeta \zeta}\left(\omega_{E}\right)$ - wave energy spectrum density function,

$\rho_{A W}\left(\omega_{E}\right)$ - added wave resistance transfer function,

$B$ - ship breadth,

$L$ - ship length,

$\rho$ - seawater density,

$g-$ acceleration due to gravity.

The added wave resistance transfer function $\rho_{\mathrm{AW}}\left(\omega_{\mathrm{E}}\right)$ was calculated in the same way as in Case 1, assuming that the encounter frequency values range within $\omega_{\mathrm{E}}=0,4-1,0 \mathrm{~s}^{-1}$ with the step of $0,05 \mathrm{~s}^{-1}$.

The function $S_{\zeta \zeta}$ was calculated under the following assumptions:

- wave parameters:

- significant wave height $\mathrm{H}_{\mathrm{s}}=3 \mathrm{~m}$,

- characteristic wave period $\mathrm{T}_{1}=8 \mathrm{~s}$,

- wave energy spectrum, according to ITTC:

$$
S_{\zeta \zeta}(\omega)=A \omega^{-5} \exp \left(-B \omega^{-4}\right)
$$

where:

$$
\begin{gathered}
A=\frac{173 \cdot H_{S}{ }^{2}}{T_{1}{ }^{4}}=\frac{173 \cdot 3^{2}}{8^{4}}=0,38 \\
B=\frac{691}{T_{1}{ }^{4}}=\frac{691}{8^{4}}=0,169
\end{gathered}
$$

The calculated values of: the added wave resistance transfer function $\rho_{\mathrm{AW}}\left(\omega_{\mathrm{E}}\right)$, the wave energy spectrum density function $S_{\zeta \zeta}\left(\omega_{E}\right)$, and the product of these functions $\rho_{A W}\left(\omega_{E}\right) S_{\zeta \zeta}\left(\omega_{E}\right)$ are given in Table 3 . Additionally, Fig. 5 shows graphically the transfer function $\rho_{\mathrm{AW}}\left(\omega_{\mathrm{E}}\right)$.

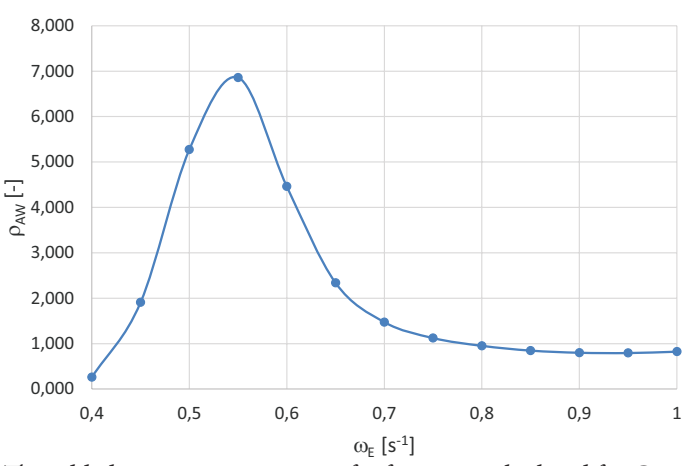

Fig. 5. The added wave resistance transfer function calculated for Case 2. Ship parameters were the following: length between perpendiculars $L_{p p}=187 \mathrm{~m}$, breadth $B=29 \mathrm{~m}$, waterplane coefficient $C W L=0,85$, speed $\stackrel{p p}{v}=15 \mathrm{w}$. 
Table 3. Sample results of calculations of: the added wave resistance transfer function $\rho_{A M}$, the wave energy spectrum density function $S_{\text {, }}$, and the product $\rho_{A W} \times S_{\zeta \zeta}$. The calculations were performed under the following assumptions: ship length between perpendiculars $L_{\text {p }}=187 \mathrm{~m}$, ship breadth $B$ $=29 \mathrm{~m}$, waterplane coefficient $C W L=0,85$,

ship speed $V=15 \mathrm{w}$, significant wave height $H_{S}=3 \mathrm{~m}$, characteristic wave period $T_{1}=8 \mathrm{~s}$.

\begin{tabular}{|l|c|c|c|c|c|c|c|c|c|c|c|c|c|c|}
\hline (1) & $\omega_{\mathrm{E}}[1 / \mathrm{s}]$ & 0,4 & 0,45 & 0,5 & 0,55 & 0,6 & 0,65 & 0,7 & 0,75 & 0,8 & 0,85 & 0,9 & 0,95 & 1 \\
\hline & & 0,26 & 1,91 & 5,27 & 6,86 & 4,6 & 2,34 & 1,47 & 1,2 & 0,95 & 0,85 & 0,8 & 0,79 & 0,82 \\
\hline
\end{tabular} \begin{tabular}{|l|c|c|c|c|c|c|c|c|c|c|c|c|c|c|}
\hline (2) & $\rho_{\text {aw }}[-]$ & 0,26 & 1,91 & 5,27 & 6,86 & 4,46 & 2,34 & 1,47 & 1,12 & 0,95 & 0,85 & 0,80 & 0,79 & 0,82 \\
\hline
\end{tabular}

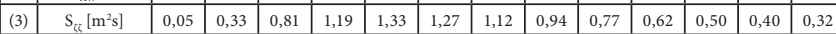

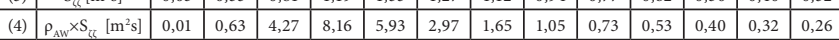

Then, making use of formula (20) and the values of $\rho_{\mathrm{AW}} \times \mathrm{S}_{\zeta \zeta}$ from line (4) in Table 3 , the statistical mean value of the added wave resistance $R_{w}$ was calculated using the trapezoidal method:

$R_{w}=1,025 \cdot 9,81 \cdot \frac{29^{2}}{187} \cdot\left(\frac{0,01}{2}+0,63+4,27+8,16+5,93+2,97+1,65+1,05+0,73+0,53+\right.$

$\left.0,4+0,32+\frac{0,26}{2}\right) \cdot 0,05=121,1 k N$

Case 3. The use of the developed method for waterplane coefficient optimisation taking into account the added wave resistance at the preliminary bulk carrier design stage.

This example presents the use of the method for finding, at the preliminary bulk carrier design stage, an optimal value of the waterplane coefficient which takes into account the added wave resistance. In the calculations the following assumptions were adopted:

- ship speed $\mathrm{V}=15$ knots,

- length between perpendiculars $\mathrm{L}_{\mathrm{pp}}=187 \mathrm{~m}$,

- breadth $\mathrm{B}=29 \mathrm{~m}$,

The aim of the design task was to calculate the waterplane coefficient value CWL within the range from 0,85 to 0,93 for which the wave resistance reaches the minimum.

The formula (20) allows to calculate the added wave resistance from a single wave of arbitrary statistical parameters. However, waves of different parameters can occur on the ship navigation route. To evaluate the ship design in a comprehensive way which takes into account a variety of waves, coefficients reflecting certain wave distributions are frequently used. An example of such a coefficient and its use in ship designing is given in [17].

In the present case the wave resistance was described using the coefficient RI which, like in [17], was defined as:

$$
R I=\sum_{i=1}^{8} R_{w}\left(H_{S}=3 m, T_{1}(i)\right) \cdot \frac{f_{T}(i)}{1000}
$$

where:

$\mathrm{R}_{\mathrm{w}}$ - statistical mean added wave resistance, calculated according to formula (20) (and the sample formula (24)),

$H_{S}$ - significant wave height,

$T_{1}$ - characteristic period of the wave having parameters from Table 4,

$f_{T}$-incidence rate of the wave of given period $\mathrm{T}_{1}$. Its value was taken from Table 4, showing the data for the Atlantic $[10$, p. 373, Table 6.4]

i - No. of line in Table 4.

The RI coefficient represents the statistical mean added wave resistance from the statistical wave having the following parameters:
- significant height $\mathrm{H}_{\mathrm{s}}=3 \mathrm{~m}$,

- characteristic period $\mathrm{T}_{1}=5-17 \mathrm{~s}$,

- different incidence rates.

Table 5 presents sample results of RI calculations for the assumed data and for the waterplane coefficient equal to $\mathrm{CWL}=0,85$.

Then the RI values were calculated for other CWL values ranging from 0,85 to 0,93 with the step of 0,1 . The results are graphically shown in Fig. 6.

It results from the diagram in Fig. 6 that the optimal CWL value taking into account the added wave resistance is $\mathrm{CWL}=0,90$. For this value the RI coefficient is the lowest.

Table 4. Incidence rates $f_{T}$ of waves of characteristic periods $T_{1}$ adopted in calculations. The data for the North Atlantic taken from [10, p. 373, Table 6.4]

\begin{tabular}{|c|c|c|}
\hline No. & $\begin{array}{c}\text { Characteristic wave period T1 } \\
{[\mathrm{s}]}\end{array}$ & \begin{tabular}{c} 
Incidence in $\begin{array}{c}1000 \text { observations } \\
\text { fT [-] }\end{array}$ \\
\hline 1
\end{tabular} \\
\hline 2 & $5-7$ & 118,97 \\
\hline 3 & $7-9$ & 345,43 \\
\hline 4 & $9-11$ & 358,72 \\
\hline 5 & $11-13$ & 138,59 \\
\hline 6 & $13-15$ & 29,05 \\
\hline 7 & $15-17$ & 5,65 \\
\hline 8 & 17 & 0,92 \\
\hline
\end{tabular}

Table 5. Sample results of RI calculations for $C W L=0,85: H_{S}-$ significant wave height, $T_{1}$ - characteristic wave period, $R_{w}$ - statistical mean added wave resistance, $f_{T}$ - incidence rate of the wave of a given characteristic period.

\begin{tabular}{|c|c|c|c|c|c|}
\hline No. $(\mathrm{i})$ & $\begin{array}{c}\mathrm{Hs} \\
{[\mathrm{m}]}\end{array}$ & $\begin{array}{c}\mathrm{T} 1 \\
{[\mathrm{~s}]}\end{array}$ & $\mathrm{Rw}[\mathrm{kN}]$ & $\begin{array}{c}\mathrm{fT} / 1000 \\
{[-]}\end{array}$ & $\begin{array}{c}\text { Rwx fT/1000 } \\
{[\mathrm{kN}]}\end{array}$ \\
\hline 1 & 3 & 5 & 15,3 & 0,119 & 1,82 \\
\hline 2 & 3 & 6 & 38,4 & 0,345 & 13,25 \\
\hline 3 & 3 & 8 & 121,2 & 0,359 & 43,51 \\
\hline 4 & 3 & 10 & 144,3 & 0,139 & 20,06 \\
\hline 5 & 3 & 12 & 110,1 & 0,029 & 3,19 \\
\hline 6 & 3 & 14 & 74,1 & 0,006 & 0,44 \\
\hline 7 & 3 & 16 & 47,9 & 0,001 & 0,05 \\
\hline 8 & 3 & 17 & 39,6 & 0,003 & 0,12 \\
\hline
\end{tabular}

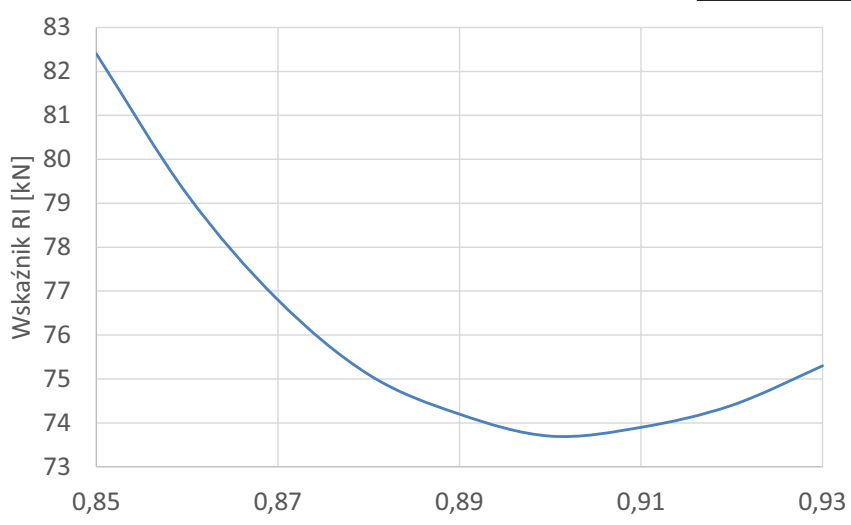

Fig. 6. RI vs. CWL in sample design task 


\section{SUMMARY}

The method and function presented in the article can be used to calculate the added wave resistance coefficient for bulk carriers having the following geometrical parameters:

- displacement $\mathrm{D}=18500$ - $56000 \mathrm{t}$,

- length between perpendiculars $\mathrm{L}_{\mathrm{pp}}=132-210 \mathrm{~m}$,

- breadth $\mathrm{B}=21$ - 32,2 m,

- draught $\mathrm{d}=7,8-12 \mathrm{~m}$,

- waterplane area $\mathrm{Fw}=2300-5600 \mathrm{~m}^{2}$,

- waterplane coefficient $\mathrm{CWL}=0,8-0,93$,

within a wide range of ship velocities $\mathrm{V}=0-8 \mathrm{~m} / \mathrm{s}$.

The parameters which are needed to calculate this function are basic parameters of the bulk carrier design, such as:

- waterplane area,

- waterplane coefficient,

and ship speed.

Within the linear theory of rolling, this function allows to calculate the mean added wave resistance for an arbitrary irregular head wave described by an arbitrary energy spectrum.

Thanks to that the developed function can have a wide range of applications, such as for instance:

- preliminary designing of bulk carriers: to take into account the added wave resistance in the resistance-propulsion characteristics,

- planning the navigation route: to work out speed characteristics of the bulk carriers with waves taken into account,

- calculating the weather factor in the energy efficiency design index, EEDI.

The article presents samples of practical use of the presented method to illustrate its applicability for calculating, for instance:

- the added wave resistance coefficient for a given encounter frequency,

- the added wave resistance transfer function,

- the statistical mean added wave resistance,

and optimising the waterplane coefficient with respect to the added wave resistance at the preliminary bulk carrier design stage.

\section{BIBLIOGRAPHY}

1. Abramowski, T.: Application of Artificial Intelligence Methods to Preliminary Design of Ships and Ship Performance Optimization, Naval Engineers Journal 125 (3), pp. 101-112, 2013.

2. Abramowski T.: Application of artificial neural networks to assessment of ship manoeuvrability qualities, Polish Maritime Research, 2008 (2), pp 15-21, 2018

3. Arribas F. Pe'rez: Some methods to obtain the added resistance of a ship advancing in waves, Ocean Engineering 34 (2007), pp. 946-955, 2007.
4. Bhattacharyya R.: Dynamics of Marine Vehicles, John Wiley \& Sons Inc, 1978

5. Cepowski T.: Approximation of Added Resistance in Waves Based on Ro-Ro Ferry Main Dimensions and Wave Parameters, Archives of Transport 02/2012; 23(4), pp. 435445,2012

6. Cepowski T.: Determination of optimum Hull form for passenger car ferry with regard to its sea-keeping qualities and added resistance in waves, Polish Maritime Research, No 2(56), Vol 15, pp 3-11, 2008

7. Cepowski T.: Modelling of Added Wave Resistance on the basis of the Ship's Design Parameters, „Computer Systems Aided Science and Engineering Work in Transport, Mechanics and Electrical Engineering", No. 121, pp. 39-46, Radom, 2008

8. Cepowski T.: On the modeling of car passenger ferryship design parameters with respect to selected sea-keeping qualities and added resistance in waves, Polish Maritime Research, No 3(61), Vol 16, pp 3-10, 2009

9. Chądzyński W.: "Elements of modern methodology of designing of floating objects (in Polish), Prace Naukowe Politechniki Szczecińskiej, Szczecin 2001

10. Dudziak J.: The theory of the ship (in Polish), Fundacja Promocji Przemysłu Okrętowego i Gospodarki Morskiej, Gdansk 2008.

11. Faltinsen, O.M., Minsaas K.J., Liapis N., Skjørdal, S..: "Prediction of Resistance and Propulsion of a Ship in a Seaway", Proceedings of the 13th Symposium on Naval Hydrodynamics, pp. 505-529, Tokyo 1980

12. Gerritsma J., Beukelman W.: Analysis of the Resistance Increase in Waves of a Fast Cargo-ship, International Shipbuilding Progress, No 18(217), 1972

13. Journée J.M.J.: Verification and Validation of Ship Motions Program SEAWAY, Report1213a, Delft University of Technology, Ship Hydromechanics Laboratory, The Netherlands, 2001

14. MATULJA D, SPORTELLI M., GUEDES SOARES C., PRPIĆ-ORŠIĆ J.: Estimation of Added Resistance of a Ship in Regular Waves, Brodogradnja, 62(2011) Vol. 3, pp 259-264

15. Nabergoj R., Jasna P.: A comparison of different methods for added resistance prediction, 22nd IWWWFB, Plitvice, Croatia 2007

16. SALVESEN, N.: "Added Resistance of Ships in Waves", Journal of Hydronautics, 1978. 
17. Szelangiewicz T.: Ship's Operational Efectiveness Factor as Criterion Cargo Ship Design Estimation, Marine Technology Transaction, Polish Academy of Sciences, Branch in Gdańsk, Vol. 11, 2000

18. Watson D.G.M: Practical Ship Design, Gulf Professional Publishing, 2002

\section{CONTACT WITH THE AUTHOR}

Tomasz Cepowski

Maritime University of Szczecin

ul. Wały Chrobrego 1-2

70-500 Szczecin

\section{Poland}

